\title{
Transient Elasto graphy- The Newer Technique for Noninvasive Assessment of Liver Fibrosis
}

\author{
Sudhir J Gupta1*, Nitin R Gaikwad ${ }^{2}$, Dharmesh K Shah ${ }^{2}$ and Nikhil U Shirole ${ }^{2}$ \\ ${ }^{1}$ Professor \& Head, Department of Gastroenterology, India \\ ${ }^{2}$ Assistant professor, Department of Gastroenterology, India
}

Submission: February 02, 2017; Published: April 19, 2017

"Corresponding author: Sudhir Gupta, Professor and head of the department, Department of Gastroenterology, Government Medical College and Super Specialty Hospital, Nagpur, Maharashtra, India, Tel: 091-0712-2750121, Email: sudhirjgupta@gmail.com

\section{Introduction}

Fibrosis is a wound healing response to injury and is a complex dynamic process involving fibrogenesis and fibrolysis. Chronic viral hepatitis or steatohepatitis leads to fibrogenesis through increased synthesis of extracellular matrix components such as collagens and glycoproteins. Assessment of fibrosis stage or the presence of cirrhosis will often dictate treatment options as well as provide an overall prognosis for patients with chronic liver disease of any etiology. Historically, liver biopsy has been the primary means of identifying fibrosis and monitoring for disease progression. However, liver biopsy is a painful, expensive, and invasive procedure with risk of potential complications [1]. The accurate evaluation of fibrosis using liver biopsy is also complicated by sampling error and inter observer variation in staging of fibrosis [2]. Given the risks of the procedure, the limited static and cross sectional information provided in relation to overall disease progression, as well as the error rate, the development of noninvasive and reliable means of evaluating for the presence of fibrosis and fibrogenesis has been an important area. Noninvasive tests of fibrosis in viral hepatitis now include a combination of serologic markers as well as imaging modalities [3]. As we progress into the era of safe and effective directly acting antiviral therapy for chronic hepatitis $\mathrm{C}$ (CHC), various serum biomarkers and imaging methods are now being validated for assessment of liver fibrosis [4].

\section{Principle of Transient Elastography}

Using an ultrasound transducer probe, vibrations of mild amplitude and low frequency $(50 \mathrm{~Hz})$ are transmitted through the liver tissue (Figure 1). This results in an elastic shear wave that propagates through the underlying liver tissue. The probe then utilizes pulse-echo ultrasound to follow the propagation of the shear wave and to measure its velocity. The velocity of the wave is directly related to tissue stiffness which correlates with fibrosis [5]. The harder the tissue, the faster the shear wave propagates. The liver stiffness is calculated from velocity and expressed in kilopascal $(\mathrm{kPa})$. This method allows for the evaluation of numerous parameters including velocity of vibration, velocity of wave propagation and elastic modulus. TE allows for the identification of disease severity due to altered mechanical properties of the fibrotic liver [6].

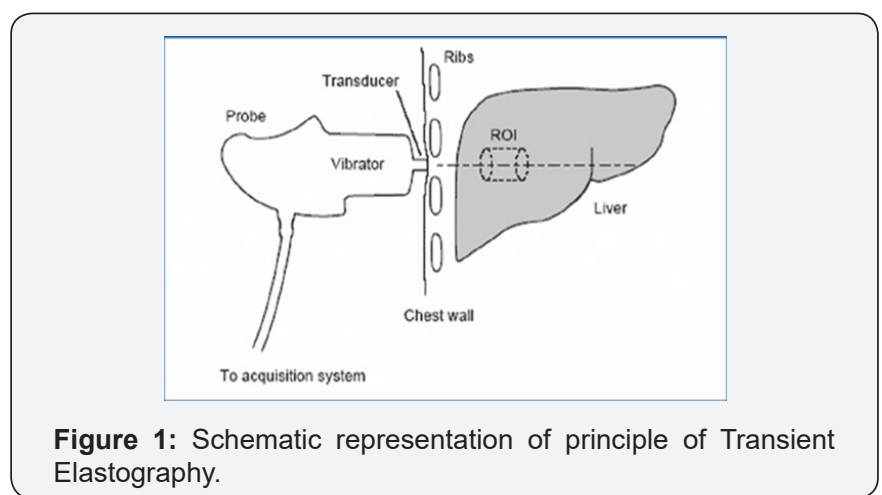

The feasibility and accuracy of liver stiffness measurement (LSM) using transient elastography device are heavily influenced by obesity and other associated factors (e.g., thoracic fold thickness, waist circumference, and the distance between the skin and liver capsule). Moreover, subcutaneous adipose tissue may lead to overestimation of liver stiffness [7]. As a result, a novel probe (the 'XL' probe) is approved for use in obese patients. This probe has a greater vibration amplitude and measurement depth compared with the standard M probe. The XL probe allows for accurate measurement of LSM in a significantly greater number of obese patients than them (9-mm probe) probe [8]. In smaller adults, the standard $\mathrm{M}$ probe (with a 9-mm tip diameter) may inaccurately assess liver stiffness because the narrow inter costal spaces in these patients. Thus, a smaller probe, the $\mathrm{S} 2$ probe, has been developed for pediatric use and, in a recent published trial by Pradhan et al. [9] the S2 and M probes were comparable with 
respect to reliability and accuracy of stiffness measurements. However, the S2 probe may over estimate liver stiffness in some patients, particularly those with a larger distance between the skin and liver capsule and should be reserved for smaller, lean patients or children.

Since fat affects the propagation of the ultrasound wave, the transient elastography can also be used to estimate liver fat content. This novel parameter, named Controlled Attenuation Parameter (CAP), measures the ultrasound attenuation at the center frequency of the $\mathrm{M}$ probe. In a preliminary retrospective study CAP assessment in 112 patients with chronic liver disease from various etiologies has shown good performances for the detection and semi quantification for steatosis [10].

\section{Procedure of Transient Elastography}

TE is a very simple and safe technique that takes 5-10 minutes and can be done in a specialty clinic or outpatient setting. The only preliminary preparation required is that patients fast for 2-3 hours prior to the procedure due to the potential increase in liver stiffness from postprandial blood flow [11]. The patient is placed in a dorsal decubitus position with the right arm in maximal abduction. The exam then begins with placement of the probe along inter costal space to obtain a view of the right lobe of the liver. Once an area of at least $6 \mathrm{~cm}$ thick and free of large vascular structures or gallbladder has been identified, ten measurements are obtained using the probe. The actual area measured by the probe has a volume that is at least 100 times bigger than the average liver biopsy sample [12].

A reliable exam should result in ten measurements with a $70 \%$ success rate, and the inter quartile range should be less than $30 \%$ of the value of the median [13]. An important aspect to any new technique is its cost effectiveness. TE has been found to be a cost-effective surveillance strategy to evaluate for the presence of fibrosis.

\section{Limitations of Transient Elastography}

TE cannot be used in individuals with ascites, and is associated with higher failure rates or unreliable results in obese patients using the standard M probe, as the shear wave does not propagate through fluid, and fat also attenuates ultrasound and elastic waves. Newer XL probes have been developed that reduce failure rates in obese patients. Fibrosis thresholds are lower than the standard M probe, and further validation in larger cohorts of chronic liver disease patients is required. Children and lean patients with narrow inter costal spaces also have higher failure rates, and newer pediatric S2 probes are now available to improve reliability in this regard. Liver stiffness values for TE may be 1.3-3 times higher in the setting of acute inflammation and/or moderate alanine amino transferase (ALT) elevation [14]. The stiffness values usually return to baseline along with the normalization of laboratory abnormalities. Hence, the use of TE in the setting of trans aminitis is not recommended. Roulot et al showed that men and patients with a body mass index $>30 \mathrm{~kg} /$ $\mathrm{m} 2$ had higher liver stiffness scores on average. After adjusting for sex and body mass index, liver stiffness values were also higher in subjects with metabolic syndrome [15]. Other limitations for accurate stiffness reading include sinusoidal congestion, extra hepatic cholestasis, TE is somewhat operator dependent. Therefore, there may be some variability in results depending on the operator. Utility of transient elastography in Hepatitis C, Hepatitis B, Nonalcoholic fatty liver disease, Cholestatic Liver Disease is already increasing.

\section{Conclusion}

Transient Elastography provides a non-invasive and reproducible tool which can be easily utilized for patient care as an adjunct to clinical evaluation for the staging of liver fibrosis. The key clinical parameter in patient management is the diagnosis or exclusion of advanced fibrosis and cirrhosis. The transient elastography is an adjunct to clinical, radiological, and biochemical evaluation and not a replacement to the liver biopsy. When elastography does not correlate well with clinical findings, use of serological tests such as APRI, Hepascore, and FibroSure/ FibroTest and liver biopsy should be considered. Utility of transient elastography in Hepatitis C, Hepatitis B, Nonalcoholic fatty liver disease, Cholestatic Liver Disease is already increasing.

\section{References}

1. Cadranel JF, Rufat P, Degos F (2000) Practices of liver biopsy in France: results of a prospective nationwide survey. For the Group of Epidemiology of the French Association for the Study of the Liver (AFEF). Hepatology 32(3): 477-481.

2. Regev A, Berho M, Jeffers LJ (2002) Sampling error and intra observer variation in liver biopsy in patients with chronic HCV infection. Am J Gastro enterol 97(10): 2614-2618.

3. Castera L (2012) Noninvasive methods to assess liver disease in patients with hepatitis B or C. Gastroenterology 142(6): 1293-1302.

4. Castera L, Vilgrain V, Angulo P (2013) Noninvasive evaluation of NAFLD. Nat Rev Gastroenterol Hepatol 10(11): 666-675.

5. Sandrin L, Fourquet B, Hasquenoph JM (2003) Transient elastography: a new noninvasive method for assessment of hepatic fibrosis. Ultra sound Med Biol. 29(12): 1705-1713.

6. Stasi C, Arena U, Vizzutti F (2009) Transient elastography for the assessment of liver fibrosis in patients with chronic viral hepatitis: the missing tool? Dig Liver Dis 41(12): 863-866.

7. Foucher J, Castera L, Bernard PH (2006) Prevalence and factors associated with failure of liver stiffness measurement using Fibro Scan in a prospective study of 2114 examinations. Eur J Gastro enteral Hepatol 18: 411-412.

8. Wong VW, Vergniol J, Wong GL (2012) Liver stiffness measurement using XL probe in patients with nonalcoholic fatty liver disease. AmJ Gastro enterol 107: 1862-1871.

9. Pradhan F, Ladak F, Tracey J (2013) Feasibility and reliability of the Fibro Scan S2 (pediatric) probe compared with the Mprobe for liver stiffness measurement in small adults with chronic liver disease. Ann Hepatol 12(1): 100-107.

10. De Lédinghen V, Vergniol J, Foucher J (2012) Non-invasive diagnosis of liver steatosis using controlled attenuation parameter (CAP) and transient elastography. Liver Int 32(6): 911-918. 
11. Arena U, Lupsor Platon M, Stasi C (2013) Liver stiffness is influenced by a standardized meal in patients with chronic hepatitis $\mathrm{C}$ virus at different stages of fibrotic evolution. Hepatology 58(1): 65-72.

12. Beaugrand M (2006) Fibroscan: instructions for use. Gastro enteral Clin Biol 30(4): 513-514.

13. Stasi C, Arena U, Vizzutti F (2009) Transient elastography for the assessment of liver fibrosis in patients with chronic viral hepatitis: the missing tool? Dig Liver Dis 41(12): 863-866.
14. Tapper EB, Cohen EB, Patel K (2012) Levels of alanine amino transferase compound use of transient elastography to diagnose fibrosis in patients with chronic hepatitis $\mathrm{C}$ virus infection. Clin Gastro enterol Hepatol 10(8): 932-937.

15. Roulot D, Czernichow S, Le Clésiau H, Costes JL, Vergnaud AC, et al. (2008) Liver stiffness values in apparently healthy subjects: influence of gender and metabolic syndrome. J Hepatol 48(4): 606-613.

Your next submission with JuniperPublishers
will reach you the below assets
- Quality Editorial service
- Swift Peer Review
- Reprints availability
- E-prints Service
- Manuscript Podcast for convenient understanding
- Global attainment for your research
- Manuscript accessibility in different formats
( Pdf, E-pub, Full Text, audio)
- Unceasing customer service
Track the below URL for one-step submission
https://juniperpublishers.com/online-submission.php

